\title{
Análise dos discursos jornalísticos sobre a lei № 13.840 e as mudanças nas políticas sobre drogas
}

\author{
Yuri Fontenelle Lima Montenegro ${ }^{1}$, Aline Veras Morais Brilhante ${ }^{1} \mathrm{e}$ \\ Christina César Praça Brasil ${ }^{1}$
}

\begin{abstract}
${ }^{1}$ Programa de Pós-Graduação em Saúde Coletiva Universidade de Fortaleza, Brasil | fontenellesh@gmail.com; alineveras@unifor.br; cpraca@unifor.br | https://orcid.org/0000 0002-3939-142X; https://orcid.org/0000-0002-3925-4898; http://orcid.org/0000-0002-7741-
\end{abstract}

Resumo: Introdução: A análise dos dispositivos legais que dispõem sobre o Sistema Nacional de Políticas Públicas sobre Drogas apontou para a mudança discursiva em direção a concepções proibicionistas e manicomiais, em oposição aos princípios da reforma psiquiátrica brasileira. Contudo, por se tratar de um documento normativo, o acesso da maior parcela da população ao conteúdo da lei ocorre pela mediação da mídia. Dessa forma, as questões que norteiam o presente artigo dizem respeito à relação entre o discurso na lei, enquanto documento normativo, e o discurso veiculado pela imprensa. Objetivos: analisar os discursos de matérias jornalísticas que veicularam a aprovação da lei $\mathrm{n}^{\circ}$ 13.840/2019, que dispõe sobre o Sistema Nacional de Políticas Públicas sobre Drogas. Métodos: Tratase de um estudo documental com aporte da Análise de Discurso Crítica de Fairclough, segundo o método de análise tridimensional. Foram analisadas matérias jornalísticas (MJ) publicadas online em quatro portais de notícia de massa - CartaCapital, The Intercept Brasil, G1 e R7 - sobre a Lei no 13.840 , de 5 de junho de 2019, entre maio e agosto de 2019. Resultados: Observou-se o predomínio de uma análise superficial, agravada pela disputa entre paradigmas sobre a questão das drogas e pela polarização política crescente no Brasil desde 2014. As fragilidades complexas da rede de assistencia psicossocial, por exemplo, não foram aprofundadas. O uso demasiado da linguagem afetiva pelas MJ, ainda que faça sentido ao receptor ideal, pode comprometer a credibilidade do emissor perante leitores não habituais. Conclusões: A celeridade pela difusão de furos e o apelo excessivo à dramatização dos acontecimentos podem levar à abordagem superficial de fenômenos complexos e ao questionamento da legitimidade da instância midiática. Tem-se, por consequência, a reprodução de relações de dominação à medida que a instância cidadã não desenvolve uma postura crítica perante as formas de governança da instância política.

Palavras-chave: Meios de Comunicação de Massa; Discurso; Política; Controle de Drogas; Políticas Públicas.

Analysis of Journalistic Discourses about the Act 13.840 and the Changes in Drug Policy

Abstract: Introduction The analisys of the Act 13.840 on the National System for Public Drug Policy points to a discoursive change towards prohibition and asylum support. It threatens the Brazilian Psychiatric Reform principles. However, most of the population will access the Act by the media. Therefore, the questions that guide this study concern about the relation between the discourse of the Act and the one produced by the press. Goals: To analyze the discourse of the news that reported the approval of the Act 13.840, on the National System for Public Drug Policy. Methods: Critical Discourse Analysis using Fairclough's three-dimensional framework. We analyzed online news about the Act 13.840 published on four mass media portals - CartaCapital, The Intercept Brasil, G1 e R7 - between may and august of 2019. Results: We found a shallow approach on the complexity and frailties of the psychosocial support network. It is worsened by the dispute between prohibition and anti-prohibition ideas and the increasing political division in Brazil since 2014. The abuse of affective language, although it may be reasonable for the ideal receiver, can jeopardize the transmitter's credibility in front of non-habitual readers. Conclusions: The eagerness for scoops and the abuse dramatization of the events may lead to a shallow approach on complex phenomenons. Hence, the media's legitimacy may be put in check.

Keywords: Mass Media; Address; Politics; Drug and Narcotic Control; Public Policy. 


\section{Introdução}

A análise dos dispositivos da lei no 13.840/2019, que dispõe sobre o Sistema Nacional de Políticas Públicas sobre Drogas, apontou a mudança discursiva em direção à tomada de medidas de controle social alinhadas a concepções proibicionistas e manicomiais, em oposição aos princípios da reforma psiquiátrica brasileira (Montenegro et al., 2020). Contudo, por se tratar de um documento normativo, o acesso da maior parcela da população ao conteúdo da lei ocorre pela mediação da mídia. Deste modo, o presente artigo propõe-se analisar os discursos de matérias jornalísticas que veicularam a aprovação da lei em questão. Dessa forma, as questões que norteiam este artigo dizem respeito à relação entre o discurso na lei, enquanto documento normativo, e o discurso veiculado pela imprensa: como é montado o discurso de uma lei e qual a natureza/papel da mídia nessa composição.

Parte-se da premissa que o discurso político deve ser compreendido em relação com o contexto psicológico e social em que é produzido, integrando conceitos de outras disciplinas sociais e humanas. Assim, o discurso político está relacionado ao exercício do poder, mas, além da linguagem, envolve um espaço e uma ação política. O espaço político está contido no espaço público, relacionando-se com outros três campos de ação social: o jurídico, o econômico e o midiático. Por sua vez, a ação política, cuja finalidade idealizada é o bem comum, diz respeito à organização dos indivíduos em comunidade, no sentido de regular relações de dominação ou conflito, orientar o comportamento dos indivíduos e delegar tarefas mediante um sistema de representação (Charaudeau, 2018). Nota-se, portanto, a relação de interdependência entre os seguintes campos de ação: político, jurídico, midiático e econômico.

No caso específico da política sobre drogas, a interdependência entre os campos de ação político, jurídico, midiático e econômico pode ser observada, por exemplo, na história do proibicionismo. Apesar de já se observar nas sociedades arcaicas a existência de mecanismos de controle social do consumo de drogas, esse fenômeno - tanto de consumo quanto de controle - assume nova dimensão e complexidade a partir da modernidade (Mota, 2009). Citam-se, para ilustrar, acordos internacionais em vista do proibicionismo e suas motivações econômicas (Carneiro, 2018; Carvalho, 2014), a existência de sanções penais contra usuários de drogas na legislação brasileira (Vargas \& Campos, 2019), a abordagem midiática, ora no campo da propaganda ora na reprodução de estereótipos equivocados (Bentes, 2017; Carlini, 2006; Ferreira \& Martini, 2001; Mota, 2009; Pasquim et al., 2020; Romanini \& Roso, 2014), e a exploração política da questão das drogas como forma de conquistar o apoio popular e reinvidicar mais verba para saúde (Fiore, 2012; Nappo et al., 2012).

Neste estudo, será considerada, especificamente, a relação entre os campos da ação política e midiática. A ação política é produzida por três instâncias: a política, lugar dos sujeitos que detêm o poder de decisão, ação e manipulação (governança), a exemplo dos representantes do Estado e dos partidos políticos, tanto de situação quanto de oposição; a cidadã, lugar de poder indireto, à medida que reage - passiva ou criticamente - ao discurso da instância política em nome de uma idealização do bem comum, e que é composta pela sociedade civil e sociedade cidadã; e a midiática, lugar de relativa independência que desempenha um papel de mediação entre as instâncias política e midiática (Charaudeau, 2018).

Diferente da instância política, a midiática está fora da governança e, portanto, não se caracteriza como uma instância de poder. O seu objetivo é a denúncia do poder, o que lhe confere legitimidade perante a instância cidadã ${ }^{1}$.

1 A busca por legitimidade ocorre a partir de uma relação entre credibilidade e captação. Dessa forma, ganha-se credibilidade ao denunciar o poder e elementos ocultos do discurso político mediante o uso da razão (logos). A captação diz respeito à dramatização dos acontecimentos - visando às paixões dos leitores (pathos) - a fim de ganhar visibilidade no mercado. 
Contudo, a relação entre as instâncias política e midiática é caracterizada por um jogo de máscaras e de manipulação mútua, onde cada qual deseja alcançar seus objetivos, quais sejam: a perpetuação do poder e a maior visibilidade no mercado, respectivamente (Charaudeau, 2019).

Situado no rol da Análise de Discurso Crítica (ADC), o presente estudo tem por objetivo discutir a complementariedade entre o discurso político e o discurso midiático para 0 estudo de políticas públicas - especificamente sobre drogas, para o trabalho em questão - a partir de uma abordagem discursiva.

\section{Método}

Trata-se de um estudo documental (Gil, 2018) de abordagem qualitativa com aporte da Análise de Discurso Crítica. Dessa forma, o estudo está situado no campo da pesquisa crítica, compreendendo a linguagem como prática social (Chouliaraki \& Fairclough, 1999; Kress, 1989; Neves, 1997). O discurso é compreendido como uma forma de representar e de agir sobre o mundo, apresentando, portanto, uma relação dialética com a estrutura social, à medida que a sua construção ocorre em um contexto específico, o qual, por sua vez, também é construído discursivamente (Fairclough, 2016).

Dentre as diversas correntes de análise do discurso, optou-se pela perspectiva crítica de Fairclough (Fairclough, 2010, 2016), segundo o método de análise tridimensional. Assim, busca-se conciliar uma análise de discurso textualmente orientada com uma teoria social, analisando o discurso em três dimensões: a) vocabulário; b) prática discursiva e c) prática social. O vocabulário diz respeito à análise do texto, como as palavras utilizadas, figuras de linguagem, elementos gramaticais, coesão e estrutura textual. A prática discursiva envolve os mecanismos de produção, distribuição e consumo do texto, incluindo a composição heterogênea do discurso (intertextualidade), ação que deseja causar (força) e a quem se dirige, e, portanto, a quem faz sentido (coerência). A prática social diz respeito, por assim dizer, à dimensão macroscópica do discurso, a exemplo da concepção de mundo (ideologia) e conjunto de alianças (hegemonia) implicados na sua produção e interpretação.

As fontes documentais utilizadas neste artigo consistem em matérias jornalísticas (MJ) publicadas online em quatro portais de notícia de massa - CartaCapital, Thelntercept Brasil, G1 e R7 - sobre a Lei oㅜ 13.840, de 5 de junho de 2019. As catorze MJ foram publicadas no período de maio a agosto de 2019 , com maior incidência no mês de junho (7), seguido pelo mês de maio (5) e agosto (2), respectivamente. O Projeto de Lei (PL) foi aprovado no Senado no dia 15 de maio de 2019 e publicado no Diário Oficial da União (DOU) no dia 5 de junho de 2019. As duas MJ publicadas em agosto dizem respeito a desdobramentos de dispositivos previstos pela lei, como a internação involuntária de "usuários de drogas" e "dependentes químicos moradores de rua", conforme vocabulário utilizado no texto publicado.

As MJ foram selecionadas em março de 2020 e analisadas até junho do mesmo ano. A coleta de dados seguiu um instrumento construído a partir das categorias do método de análise tridimensional de Fairclough (2016). O instrumento consistiu em uma tabela a ser preenchida com os dados a seguir: a) título; b) autor; c) portal; d) texto (vocabulário, gramática, coesão e estrutura textual); e) prática discursiva (força, coerência e intertextualidade); e f) prática social (ideologia e hegemonia), conforme ilustrado na figura 1. Convém destacar que, apesar do uso do instrumento, não há um procedimento rígido/fixo para a realização da análise, e é possível que alguma categoria ou dimensão obtenha destaque a depender do gênero discursivo (Fairclough, 2016). O presente recorte irá enfatizar as dimensões de prática discursiva e social. 


\begin{tabular}{|c|c|}
\hline Título & \\
\hline Aeículo & \\
\hline \multicolumn{2}{|c|}{ Texto } \\
\hline $\begin{array}{c}\text { Vocabulário } \\
\text { (Significados, lexicalização e metáforas) }\end{array}$ \\
\hline $\begin{array}{c}\text { Gramática } \\
\text { (Transitividade e tema) }\end{array}$ \\
\hline $\begin{array}{c}\text { Coesão } \\
\text { (Conectivos e argumentação) }\end{array}$ \\
\hline $\begin{array}{c}\text { Estrutura textual } \\
\text { (Organização de idelas) }\end{array}$ \\
\hline \begin{tabular}{c} 
Força Prática discursiva \\
\hline (Ação convocada)
\end{tabular} \\
\hline $\begin{array}{c}\text { Coerência } \\
\text { (A quem se dirige?) }\end{array}$ \\
\hline Intertextualidade \\
\hline (Fragmentos de outros textos) \\
\hline Prática social \\
\hline Hegemonia & \\
\hline
\end{tabular}

Fig. 1. Instrumento de coleta de dados elaborado pelo autor.

Os dados registrados no instrumento de coleta foram utilizados para produzir uma síntese do discurso produzido pelos quatro portais de notícia, os quais foram escolhidos devido à sua credibilidade nacional, acesso gratuito e alinhamentos políticos distintos entre os veículos em questão. Antes da análise, já se esperava uma posição convergente à posição governista por parte do R7 e uma postura progressista e de oposição da CartaCapital e Thelntercept Brasil. Quanto ao G1, esperava-se um discurso escorregadio, de alinhamento político-ideológico transitório e aspectos implícitos/ocultos de relevância.

Considerar o posicionamento político-ideológico do portal é importante porque a mídia ocupa um lugar de mediação entre a instância política e a cidadã, desempenhando, assim, um papel estratégico nas relações de poder. A instância midiática tanto produz discursivamente o acontecimento por ela veiculado quanto escolhe o quê e como será veiculado, conferindo maior visibilidade a alguns acontecimentos em detrimento de outros. Desempenha, portanto, papel relevante na formação das consciências/imaginário social da instância cidadã. Dessa forma, embora se proponha a denunciar o poder, o discurso produzido pela instância midiática pode reproduzir estereótipos e reforçar formas de dominação (Biroli, 2011; Brittos \& Gastaldo, 2006; Lopez \& Dittrich, 2005; Sousa, 2012).

O presente estudo considerou um dispositivo específico da instância midiática - a imprensa, caracterizada pelo uso da linguagem escrita, ausência física e distanciamento do leitor. A identidade da mídia, enquanto emissor, transita entre o papel de mediador entre o leitor e o acontecimento, e o de revelador do que estava oculto. Contudo, a identidade real do receptor é uma incógnita para o emissor, o qual pode apenas estimar um receptor ideal para o qual adequa seu discurso (Charaudeau, 2019).

Consideramos que o acontecimento noticiado pela mídia também é produzido discursivamente. Dessa forma, o acontecimento é interpretado pelo emissor e reinterpretado pelo receptor, o que pode acontecer da forma esperada pelo emissor - no caso do receptor ideal - ou não. Dessa forma, produz-se uma verdade relativa, havendo distinção entre valor de verdade - quando assentado na razão e em argumentos objetivos - e efeito de verdade - quando dirigidos pelas crenças e subjetividade. $O$ apelo à linguagem afetiva, com ênfase nas crenças e subjetividade, a fim de provocar reações nos leitores, é uma estratégia de captação de público consumidor, pois a instância midiática também está inserida em uma lógica econômica (Charaudeau, 2019).

As características descritas acima sobre o discurso das mídias são relevantes para a análise da dimensão da prática discursiva, principalmente no que diz respeito à produção e o consumo das notícias produzidas pelos quatro portais de massa. 
Dessa forma, amplia-se a complexidade dos processos implicados na representação que a mídia produz sobre o discurso político. É esta representação que será consumida pela maior parte da instância cidadã, uma vez que é mais comum o acesso à notícia do que às fontes primárias. Ademais, em certa proporção, o acontecimento tanto é relatado quanto comentado pela mídia (Charaudeau, 2019), o que repercute na formação da opinião pública.

Convém destacar que a pesquisa em questão dispensa aprovação por Comitê de Ética em Pesquisa, segundo a Resolução CNS/MS 466/12, por se tratar de um estudo documental com uso de fontes disponíveis em domínio público.

\section{Resultados}

Os resultados obtidos evidenciaram que a posição das $\mathrm{MJ}$ publicadas pelos portais correspondeu à expectativa dos autores no período de seleção das fontes documentais. As $\mathrm{MJ}$ publicadas pelo $\mathrm{R} 7$ apresentam uma posição conformista e de apoio às medidas do governo, sem contextualizar o impacto da aprovação da lei na política sobre drogas e dando voz apenas a pessoas que à época compunham a base governista. A CartaCapital e o Thelntercept Brasil, por outro lado, publicaram MJ de teor crítico à aprovação da lei, ora utilizando uma linguagem racional, ora afetiva. O G1, por sua vez, publicou MJ de caráter mais diverso, com comentários de diversos especialistas que pontuam a importância da internação, mas reiteram a preocupação com sua banalização. Observase, porém, escassez na apresentação de alternativas às medidas reforçadas pelos dispositivos da lei.

Apenas quatro MJ fazem alguma menção à Rede de Atenção Psicossocial (RAPS). Dentre estas, duas foram publicadas pela CartaCapital, mas, em uma delas, predomina uma linguagem afetiva no intuito de inflamar a oposição contra as medidas do governo, representado de forma tirânica (Guimarães, 2019). A outra MJ publicada pelo mesmo portal apresenta, a partir dos comentários de um especialista, os Centros de Atenção Psicossocial (CAPS) como alternativas à internação. Ademais, problematiza o impacto de medidas de internação em massa no processo de trabalho dos profissionais da atenção psicossocial, principalmente na relação de confiança e capacidade de estabelecer vínculos com a população atendida (Basilio, 2019). A MJ publicada pelo Thelntercept Brasil contextualiza a ênfase conferida à internação pela lei com as diretrizes do SUS e denuncia os interesses ocultos, pois o incentivo da lei às Comunidades Terapêuticas (CT) beneficia a bancada evangélica, envolvida ativamente na aprovação da mesma. Aborda, ainda, a relação entre a falta de serviços das RAPS e a consolidação das CT como única oferta de tratamento em diversos municípios (Levy \& Ferraz, 2019). Uma MJ publicada pelo G1 apresenta um breve debate sobre alguns dispositivos da lei após a aprovação no Senado. Apresenta, então, o posicionamento de um senador da oposição em defesa da RAPS quando confrontado pela proposta da CT (Garcia, 2019). Por fim, convém citar outra MJ publicada pelo G1, em junho de 2019 - também montada a partir dos comentários de diversos especialistas - que faz menção a uma "abordagem motivacional psicossocial" que se contrapõe à internação involuntária, mas que "não é o foco da política atual" por ser "um processo demorado" e não produzir resultados imediatos na maioria das vezes (Nascimento, 2019).

\section{Discussão}

A menção, ou não, à RAPS e o modo como ocorre torna-se relevante para a compreensão da prática discursiva no presente estudo devido ao contexto político-social em que a lei foi sancionada e as notícias publicadas. A reforma psiquiátrica brasileira gerou mudanças substanciais nas políticas públicas de saúde mental no país, inclusive as voltadas para pessoas com transtornos devido ao uso de álcool e outras drogas. Houve uma mudança na forma de conceber o tratamento compulsório e manicomial, pautado por sanções médico-jurídicas, para uma abordagem comunitária, territorial e tolerante para com as estratégias de redução de danos (Fiore, 2005; Vargas \& Campos, 2019). 
Contudo, a tensão entre paradigmas e o embate entre posicionamentos opostos sobre a questão das drogas perdurou no século XXI (Teixeira et al., 2017).

Durante os últimos anos tem se observado um fortalecimento da atenção hospitalar e do acolhimento em CT como modelos de tratamento de pessoas com transtorno em decorrência do abuso de álcool e outras drogas em detrimento dos CAPS. Isso é o observado de forma institucional, no âmbito das políticas públicas e no discurso de membros da instância política (Delgado, 2019; Guimarães \& Rosa, 2019; Nunes et al., 2019). É nesse contexto que ocorre tanto a produção da lei quanto das MJ que a noticiam. Portanto, mencionar, ou não, o impacto do referido documento normativo na RAPS reflete uma tomada de posição, endossando ou resistindo à ideologia que o atravessa.

Outra questão a ser observada, porém, diz respeito à forma de abordar a RAPS e de produzir a própria MJ. O processo de implementação da reforma psiquiátrica brasileira tem sofrido resistência apesar dos avanços substanciais. A literatura aponta que a rede de atenção a pessoas com transtornos decorrentes do uso de álcool e outras drogas ainda é insuficiente, que há sobrecarga de trabalho, dificuldades de articulação intra e intersetorial e uma lógica de cuidado que não contribui para a independência dos usuários à medida que centralizam o tratamento exclusivamente no CAPSad (Pereira et al., 2017; Pinho et al., 2017; Pires et al., 2016; Wandekoken et al., 2015). As fragilidades são demasiadamente complexas para serem abordadas de forma superficial e são agravadas pela disputa entre paradigmas sobre a questão das drogas (Fagundes Júnior et al., 2016).

Dessa forma, considerando a crescente polarização política no país desde 2014, é possível que o uso demasiado da linguagem afetiva, ainda que faça sentido ao receptor ideal, pode comprometer a credibilidade do emissor perante leitores não habituais. Consequentemente, mesmo as MJ que apresentem argumentos lógico-racionais em favor da RAPS podem ser equivocadamente desconsideradas devido ao portal que a publicou, a exemplo dos dois textos da CartaCapital que compuseram o corpus do presente estudo. Afinal, a celeridade para produzir e difundir "furos" e a dramatização excessiva dos acontecimentos são dois fatores que levam ao questionamento da legimitidade da instância midiática (Charaudeau, 2019).

\section{Conclusões}

O trabalho descreve o percurso escolhido pelos autores para empreender uma análise de discurso crítica a partir de fontes documentais, justificando tanto a definição do corpus quanto a forma de sintetizar os dados e organizá-los em uma análise que vai além do texto. Apresenta, ainda, uma contextualização com aporte das ciências sociais e humanas que enfatiza a relevâncias dessas áreas do conhecimento para abordar questões complexas no campo da saúde, especificamente o uso de drogas e as políticas públicas sobre 0 assunto.

A análise do discurso midiático contribuiu para a compreensão dos modos e mecanismos de alcance do discurso produzido pela instância política sobre a política sobre drogas junto à instância cidadã. Assim, observou-se que as $\mathrm{MJ}$ analisadas citaram de forma superficial elementos histórico-sociais importantes, ao abordar as mudanças na política sobre drogas. Destaca-se a falta de contextualização sobre as alternativas à internação e às CTs a partir da reforma psiquiátrica brasileira e a fragilização da RAPS, questões importantes para compreender o que está em jogo com a promulgação da lei no 13.840/2019.

A leitura de documentos normativos não é prática habitual da maior parte da população, sendo informada, portanto, pela representação produzida pela instância midiática. Contudo, a celeridade pela difusão de furos e o apelo excessivo à dramatização dos acontecimentos podem levar à abordagem superficial de fenômenos complexos e ao questionamento da legitimidade da instância midiática. Tem-se, por consequência, a reprodução de relações de dominação à medida que a instância cidadã não desenvolve uma postura crítica perante as formas de governança da instância política. 


\section{Referências}

Basilio, A. L. (2019). Internação involuntária de usuário de drogas é retrocesso, diz psiquiatra. Carta Capital. https://www.cartacapital.com.br/sociedade/internacao-involuntaria-de-usuarioe-retrocesso-diz-psiquiatra/\#: :text=O especialista entende que é,direitos é entendida como tratamento.

Bentes, I. (2017). A política de enfrentamento como produtora de dano: a epidemia de crack no contexto da saúde pública contemporânea. BIS - Boletim Do Instituto de Saúde, 18(1), 4147.

Biroli, F. (2011). Mídia, tipificação e exercícios de poder: a reprodução dos estereótipos no discurso jornalístico. Revista Brasileira de Ciência Política, 6, 71-98. https://doi.org/10.1590/s0103-33522011000200004.

Brittos, V. C., \& Gastaldo, É. (2006). Mídia, poder e controle social. ALCEU, 7(13), 121-133. http://revistaalceu.com.puc-rio.br/media/alceu_n13_Brittos e Gastaldo.pdf

Carlini, E. A. (2006). A história da maconha no Brasil. Jornal Brasileiro de Psiquiatria, 55(4), 314 317.

Carneiro, H. (2018). Drogas: a história do proibicionismo. Autonomia Literária.

Carvalho, J. C. de. (2014). A emergência da política mundial de drogas: o Brasil e as primeiras conferências internacionais do ópio. Oficina Do Historiador, 7(1), 153-176. https://doi.org/10.15448/2178-3748.2014.1.15927

Charaudeau, P. (2018). Discurso político (2nd ed.). Contexto.

Charaudeau, P. (2019). Discurso das mídias (2nd ed.). Contexto.

Chouliaraki, L., \& Fairclough, N. (1999). Discourse in late modernity: rethinking critical discourse analysis. Edinburgh University Press.

Delgado, P. G. (2019). Reforma psiquiátrica: estratégias para resistir ao desmonte. Trabalho, Educação e Saúde, 17(2), 1-4. https://doi.org/10.1590/1981-7746-sol00212

Fagundes Júnior, H. M., Desviat, M., \& Silva, P. R. F. da. (2016). Reforma Psiquiátrica no Rio de Janeiro: situação atual e perspectivas futuras. Ciência \& Saúde Coletiva, 21(5), 1449-1460. https://doi.org/10.1590/1413-81232015215.00872016

Fairclough, N. (2010). A dialética do discurso. Revista Teias, 11(22), 225-234.

Fairclough, N. (2016). Discurso e mudança social (2nd ed.). Universidade de Brasília.

Ferreira, P. E. M., \& Martini, R. K. (2001). Cocaína: lendas, história e abuso. Revista Brasileira de Psiquiatria, 23(2), 96-99. https://doi.org/10.1590/S1516-44462001000200008

Fiore, M. (2005). A medicalização da questão do uso de drogas no Brasil: reflexões acerca de debates institucionais e jurídicos. In R. P. Venâncio \& H. Carneiro (Eds.), Álcool e drogas na história do Brasil. (pp. 257-290). Alameda.

Fiore, M. (2012). O lugar do Estado na questão das drogas: O paradigma proibicionista e as alternativas. Novos Estudos CEBRAP, 1(92), 9-21. https://doi.org/10.1590/S010133002012000100002

Garcia, G. (2019). Senado aprova projeto que prevê internação involuntária de dependentes químicos. G1 Política. https://g1.globo.com/politica/noticia/2019/05/15/senado-aprovaprojeto-que-preve-internacao-involuntaria-de-dependentes-quimicos.ghtml

Gil, A. C. (2018). Como elaborar projetos de pesquisa (6th ed.). Atlas.

Guimarães, T. (2019). Bicho de sete cabeças momento em que o fundamentalismo. Carta Capital. https://www.cartacapital.com.br/justica/bicho-de-sete-cabecas/

Guimarães, T. de A. A., \& Rosa, L. C. dos S. (2019). A remanicomialização do cuidado em saúde mental no Brasil no período de 2010-2019: análise de uma conjuntura antirreformista. $O$ Social Em Questão, 22(44), 111-138.

Kress, G. (1989). Linguistic processes in sociocultural practice. Oxford University Press. 
Levy, C., \& Ferraz, T. (2019). Quem ganha com a nova lei de drogas não são os dependentes químicos - são os donos de clínicas. The Intercept Brasil.

https://theintercept.com/2019/05/16/nova-lei-drogas-donos-clinicas/

Lopez, D. C., \& Dittrich, I. J. (2005). A mídia brasileira e a noção de poder em Foucault. Biblioteca On-Line de Ciências Da Comunicação, 1-10. www. bocc. ubi. pt

Montenegro, Y. F. L., Paixão, A. K. R., Sales, N. C. M., Brilhante, A. V. M., \& Brasil, C. C. P. (2020). A Análise de Discurso Crítica no estudo de políticas públicas de saúde: exemplo a partir de mudanças na política sobre drogas no Brasil. In L. Fornari, F. Freitas, E. S. F. de Oliveira, C. Oliveira, \& A. P. Costa (Eds.), New Trends In Qualitative Research (3rd ed., pp. 678-690). Ludomedia.

Mota, L. (2009). Dependência química e representações sociais: pecado, crime ou doença? Juruá

Nappo, S. A., Sanchez, Z. M., \& Ribeiro, L. A. (2012). Is there a crack epidemic among students in Brazil? Comments on media and public health issues. Cadernos de Saúde Pública, 28(9), 1643-1649. https://doi.org/10.1590/s0102-311x2012000900004

Nascimento, T. (2019). Ceará registra, em média , 42 internações involuntárias de dependentes químicos por mês. G1 Ceará. https://g1.globo.com/ce/ceara/noticia/2019/06/08/ceararegistra-em-media-87-internacoes-involuntarias-de-dependentes-quimicos-por-mes.ghtml

Neves, M. H. de M. (1997). A gramática funcional. Martins Fontes.

Nunes, M. de O., Lima Júnior, J. M. de, Portugal, C. M., \& Torrenté, M. de. (2019). Reforma e contrarreforma psiquiátrica: análise de uma crise sociopolítica e sanitária a nível nacional e regional Psychiatric reform and counter-reform: an analysis of a socio-political and sanitary crisis at national and regional level. Ciência \& Saúde Coletiva, 24(12), 4489-4498. https://doi.org/10.1590/1413-812320182412.25252019

Pasquim, H., Oliveira, M., \& Soares, C. B. (2020). Fake news sobre drogas: pós-verdade e desinformação. Saude e Sociedade, 29(2). https://doi.org/10.1590/s0104-12902020190342

Pereira, M. O., Oliveira, M. A. F. de, Pinho, P. H., Claro, H. G., Gonçalves, A. M., \& Reinaldo, A. M. dos S. (2017). Qual é a tônica da política de drogas brasileiras: ressocialização ou internamento? Escola Anna Nery, 21(3), 1-9. https://doi.org/10.1590/2177-9465-ean-20170044

Pinho, L. B. de, Silva, A. B. da, Siniak, D. S., Folador, B., \& Araújo, L. B. de. (2017). Análise da articulação da rede para o cuidado ao usuário de crack. Revista Baiana de Enfermagem, 31(1), 1-9. https://doi.org/10.18471/rbe.v31i1.16654

Pires, L. F. B., Macedo, L. G. de, Aleluia Júnior, J. A. de, Freitas, P. H. B. de, Cavalcante, R. B., \& Machado, R. M. (2016). Estratégia saúde da família e assistência ao dependente químico: ações conjuntas ou isoladas? Revista Eletrônica de Enfermagem, 18(1), 1-11. https://doi.org/10.5216/ree.v18.39177

Romanini, M., \& Roso, A. (2014). Midiatização do crack e estigmatização: corpos habitados por histórias e cicatrizes. Interface: Communication, Health, Education, 18(49), 363-376. https://doi.org/10.1590/1807-57622013.0138

Sousa, C. P. de M. e. (2012). Discurso e mídia: as relações de poder nas/das revistas. Estudos Linguísticos, 41(3), 926-935.

Teixeira, M. B., Ramôa, M. de L., Engstrom, E., \& Ribeiro, J. M. (2017). Tensões paradigmáticas nas políticas públicas sobre drogas: análise da legislação brasileira no período de 2000 a 2016. Ciência \& Saúde Coletiva, 22(5), 1455-1466. https://doi.org/10.1590/141381232017225.32772016

Vargas, A. de F. M., \& Campos, M. M. (2019). A trajetória das políticas de saúde mental e de álcool e outras drogas no século XX. Ciência \& Saúde Coletiva, 24(3), 1041-1050. https://doi.org/10.1590/1413-81232018243.34492016

Wandekoken, K., Quintanilha, B., \& Dalbello-Araujo, M. (2015). Biopolítica na assistência aos usuários de álcool e outras drogas. Revista Subjetividades, 15(3), 389-397. 